\title{
Proceeding
}

9th INSHS International Christmas Sport Scientific Conference, 4-6 December 2014. International Network of Sport and Health

Science. Szombathely, Hungary

\section{Sport skills and mental health}

\author{
GAETANO RAIOLA \\ University Parthenope, Napoli, Italy
}

\begin{abstract}
Raiola, R. (2015). Sport skills and mental health. J. Hum. Sport Exerc., 9(Proc1), pp.S369-S376. From a study previously published on the occasion of the scientific meeting of the International Conference on Sports Science and Disability held in Naples at the University Naval February 15, 2014, be clear that "It is appropriate to the study of a process for the effective implementation of these activities and connected to an objective evaluation tool". This work illustrates a practice used for a pilot project currently underway. Analysis of the practices used. Administering tests validated (FPS, POMS, tests Rockfort, measurement bmi) to an experimental group and a control group. They were also used additional assessment instruments calibrated for the specific use. Graphical representation of the data obtained. The analysis of currently available data is positive, this data will be compared with the final data to get a picture more complete. In Conclusions the data collected if confirmed by the end of the pilot project to encourage the creation of an experimental project in which they are involved more patients and more facilities in order to evaluate the results. Key words: VADO, FPS, POMS, TESTS ROCKFORT, MEASUREMENT BMI.
\end{abstract}

\footnotetext{
Corresponding author. University Parthenope, Via Berenice 11, Napoli, Italy E-mail: raiolagaetano@libero.it

9th INSHS International Christmas Sport Scientific Conference, 4-6 December 2014. International Network of Sport and Health Science. Szombathely, Hungary.

JOURNAL OF HUMAN SPORT \& EXERCISE ISSN 1988-5202

(c) Faculty of Education. University of Alicante doi:10.14198/jhse.2015.10.Proc1.27
} 


\section{INTRODUCTION}

The use of physical and sport practice is used in a widespread manner in the world of mental health. The motor control in mental health issue has the basis in traditional theoretical and argumentative study (Raiola, 2014a), in the same way it can talk on learnings and sport skills (Altavilla et. al., 2014) and in games sport also for special needs (Gaetano, 2012ab).

Self-efficacy (Gomez Paloma et al., 2014) is the main aspects for special needs and mental health and is the basis to develop the strategy for inclusion. It is recognized as a valuable tool for the prevention and as a tool to improve the therapeutic compliance. Proves to be a useful tool for rehabilitation according to the method VADO-Evaluation Activities and Objectives Definition- (Biddle, 2000; Craft et al., 1998; Kurzthaler et al., 2005) mentioned in the guidelines for national treatment programs and has a positive effect in the Rating Scale (FPS Operation Personal and Social). The twelfth meeting of the SIEP (Italian Society of Psychiatric Epidemiology) which had as its theme the physical activity and sport in mental health describes these approaches as effective, but not efficient (Alberti, 2009), and too heterogeneous as finding the critical point of the difficulty of the practice is not unified and I 'absence of a network that puts in communication these realities. From a study previously published on the occasion of the scientific meeting of the International Conference on Sports Science and Disability be held in Naples at the University Naval February 15,2014 , be clear that "It is appropriate to the study of a process for the effective implementation of these activities and connected to an objective evaluation tool. From here started the study of a practice (Carozza, 2003), which is used for a pilot project currently underway in the context of physical activity and sport in a structure that deals with mental health in Nocera Inferiore (Salerno, Italy). The aim of the research is to describe the practices used, describes and analyses the partial results (since the project is still in progress) for a first evaluation which should then be integrated with the final results to determine whether to switch to an experimental project in which they are involved more patients and more structures.

Description of practice, administration of validated test (VPS, POMS, Walking Test) to an experimental group and a control group. Graphical representation of data. Practice: The patients were divided to two typologies.

- The first includes patients under treatment at the mental health center under a participation in the daily activities of the day care center. The patients of this group carry out their life outside of the mental health center and live alone or with family.

- The second group includes patients housed in facility.

\section{MATERIAL AND METHODS}

The needs of the two groups are different, for the first group socialization activities are targeted to the achievement of the state of form and preventive factors. For the second group the activities are aimed at primary prevention and tertiary education, since the patients of advanced age and with low interaction skills (Giuliani et al., 2005). Therefore we try to maintain the functional articulation, circulatory functions and stimulate cognitive functions. Patients in the first group have carried out three days a week. The activities were soccer, light jogging and fast walking. The objectives were to control weight, improve aerobic capacity and the relationship with his own body. The events were held in groups to promote socialization and the return to social life. In addition, through sport you can increase your score FPS (personal and social functioning), which describes the state of the disease but rather the quality of life of the patient that is projected to turn on the family. All patients in the first group have carried out the same activities. Patients in 
the second group were divided into more specific objectives, the areas on which to work were as follows: general articular activation, maintenance and improvement of the functions aerobic, toning the major postural muscle groups, stimulation of cognitive and spatial system (prevention of accidents and falls). The activities have been agreed with the medical team and have created specific boards for the evaluation of the individual patient and for the monitoring of results, integrated into PTRI (Individual Rehabilitation Treatment Plan). The project duration is three months. In this study we evaluate the results obtained in the pipeline being in the middle of the total length. Were examined in 5 patients spending half a day and 5 patients guests in facility. Was identified the same number of patients with similar characteristics to be assessed as a control group. For this purpose, the following tests were administered before the start and at half-going activities:

For patient of half day therapy

- POMS test,

- Rockfort test,

- measuring BMI,

- scale FPS (personal and social functioning).

For users in charge of the facility were used as assessment tools:

- The time taken to traverse a path that contains all the elements of everyday life (walking, climbing stairs, sitting down and avoid bumping into objects).

- The time taken to stack type coins of different sizes.

- Participation in the exercise session.

- The ability to perform the exercises with an indicator from 0 to 10 , where 10 indicates the proper execution of the exercises

The results obtained have been collected in the following tables and then graphed.

\section{RESULTS}

The results obtained have been collected in the following tables and figures. 
Table 1. Results in experimental group

\begin{tabular}{|c|c|c|c|c|c|c|c|c|c|c|c|c|}
\hline \multirow[b]{3}{*}{ P1SD } & \multicolumn{3}{|c|}{ Body Mass Index } & \multicolumn{3}{|c|}{ Rockport test (Perf. Ind.) } & \multicolumn{3}{|c|}{ Poms (disturbance scale) } & \multicolumn{3}{|c|}{ ScoreFps (da Vado) } \\
\hline & \multirow[t]{2}{*}{ initial } & \multicolumn{2}{|c|}{ intermediate final } & \multirow[t]{2}{*}{ initial } & \multicolumn{2}{|c|}{ intermediate final } & \multirow[t]{2}{*}{ initial } & \multicolumn{2}{|c|}{ intermediate final } & \multirow[t]{2}{*}{ initial } & \multicolumn{2}{|c|}{ intermediate final } \\
\hline & & 24,6 & $?$ & & 44,5 & $?$ & & 86 & $?$ & & 69 & ? \\
\hline P2SD & 33,2 & 31 & $?$ & 33,2 & 38 & $?$ & 119 & 92 & $?$ & 45 & 48 & ? \\
\hline P3SD & 29 & 28,1 & $?$ & 36,4 & 42,1 & $?$ & 110 & 93 & $?$ & 42 & 49 & ? \\
\hline P4SD & 25 & 25,1 & $?$ & 38,9 & 45 & $?$ & 106 & 87 & $?$ & 35 & 45 & ? \\
\hline P5SD & 32,1 & 31 & ? & 35,5 & 39 & ? & 95 & 75 & ? & 54 & 59 & ? \\
\hline
\end{tabular}

\begin{tabular}{|c|c|c|c|c|c|c|c|c|c|c|c|c|c|}
\hline \multirow[b]{3}{*}{ P1SR } & \multicolumn{3}{|c|}{ Course(time in seconds) } & \multicolumn{4}{|c|}{ Participation in exercises } & \multicolumn{3}{|c|}{ Perfororming exercises } & \multicolumn{3}{|c|}{ Dexterity Test } \\
\hline & \multirow[t]{2}{*}{ initial } & \multicolumn{2}{|c|}{ intermediate final } & \multirow[t]{2}{*}{ initial } & \multicolumn{3}{|c|}{ intermediate final } & \multirow[t]{2}{*}{ initial } & \multicolumn{2}{|c|}{ intermediate final } & \multirow[t]{2}{*}{ initial } & \multicolumn{2}{|c|}{ intermediate final } \\
\hline & & 290 & $?$ & & 6 & 7 & $?$ & & 9 & ? & & 265 & ? \\
\hline P2SR & 320 & 280 & $?$ & & 7 & 9 & $?$ & 5 & 8 & ? & 320 & 283 & ? \\
\hline P3SR & 334 & 286 & $?$ & & 7 & 9 & $?$ & 7 & 9 & ? & 355 & 290 & ? \\
\hline P4SR & 254 & 244 & ? & & 9 & 9 & $?$ & 10 & 10 & $?$ & 276 & 264 & $?$ \\
\hline P5SR & 260 & 250 & ? & & 9 & 9 & ? & 9 & 10 & ? & 283 & 277 & ? \\
\hline
\end{tabular}

\begin{tabular}{|l|l|l|l|}
\hline $\begin{array}{l}\text { The estimated time to } \\
\text { complete the course }\end{array}$ & $\begin{array}{l}\text { participation is evaluated by assigning a score } \\
\text { and adding a score of } 3 \text { meetings. Values: } 0 \text { No } \\
\text { participation parecipazione } 1 \text { until mid-2 } \\
\text { activity participation for most of } 3 \text { full } \\
\text { participation }\end{array}$ & $\begin{array}{l}\text { score: } 0 \text { difficulty in all } 10 \text { no difficulty } \\
\end{array}$ & $\begin{array}{c}\text { Is evaluated once used to stack } \\
\text { coins of different sizes }\end{array}$ \\
\hline
\end{tabular}

Table 2. Results in control group

\begin{tabular}{|c|c|c|c|c|c|c|c|c|c|c|}
\hline \multirow[b]{3}{*}{ P1CD } & \multicolumn{3}{|c|}{ Body Mass Index } & \multicolumn{2}{|c|}{ Rockport test (Perf. Ind.) } & \multicolumn{2}{|c|}{ Poms (disturbance scale) } & \multicolumn{3}{|c|}{ ScoreFps (da Vado) } \\
\hline & \multirow{2}{*}{\begin{tabular}{|r} 
initial \\
27
\end{tabular}} & \multicolumn{2}{|c|}{ intermediate final } & \multirow[t]{2}{*}{ initial } & intermediate final & \multirow[t]{2}{*}{ initial } & intermediate final & \multirow[t]{2}{*}{ initial } & \multicolumn{2}{|c|}{ intermediate final } \\
\hline & & 27,2 & $?$ & & 36,3 & & 101 & & 62 & ? \\
\hline P2CD & 33,1 & 33 & $?$ & 34,3 & 33 & 98 & 97 & 41 & 41 & ? \\
\hline P3CD & 32,3 & 32,3 & $?$ & 35,4 & 35,9 & 111 & 120 & 38 & 36 & ? \\
\hline P4CD & 28,4 & 28,6 & ? & 37,4 & 36,8 & 87 & 90 & 52 & 52 & ? \\
\hline P5CD & 26,8 & 26,6 & ? & 38,8 & 39,2 & 99 & 97 & 44 & 46 & ? \\
\hline
\end{tabular}

\begin{tabular}{|c|c|c|c|c|c|c|c|c|c|}
\hline \multirow[b]{3}{*}{ P1CR } & \multicolumn{2}{|c|}{ Course(time in seconds) } & \multicolumn{3}{|c|}{ Participation in exercises } & \multicolumn{2}{|c|}{ Perfororming exercises } & \multicolumn{2}{|c|}{ Dexterity Test } \\
\hline & \multirow{2}{*}{\begin{tabular}{|r|} 
initial \\
271 \\
\end{tabular}} & \multirow{2}{*}{$\begin{array}{c}\text { intermediate final } \\
266\end{array}$} & \multirow{2}{*}{\begin{tabular}{|l} 
initial \\
n.d.
\end{tabular}} & \multicolumn{2}{|c|}{ intermediate final } & \multirow[t]{2}{*}{ initial } & intermediate final & \multicolumn{2}{|c|}{ initial intermediate fina } \\
\hline & & & & n.d. & n.d. & & 6 & 281 & 279 \\
\hline P2CR & 299 & 283 & n.d. & n.d. & n.d. & 6 & 7 & 317 & 299 \\
\hline P3CR & 345 & 330 & n.d. & n.d. & n.d. & 6 & 6 & 384 & 378 \\
\hline P4CR & 274 & 280 & n.d. & n.d. & n.d. & 10 & 10 & 285 & 292 \\
\hline P5CR & 305 & 310 & n.d. & n.d. & n.d. & 7 & 7 & 333 & 326 \\
\hline
\end{tabular}

\begin{tabular}{|c|c|c|c|}
\hline $\begin{array}{l}\text { The estimated time to } \\
\text { complete the course }\end{array}$ & $\begin{array}{l}\text { participation is evaluated by assigning a score } \\
\text { and adding a score of } 3 \text { meetings. Values: } 0 \text { No } \\
\text { participation parecipazione } 1 \text { until mid-2 } \\
\text { activity participation for most of } 3 \text { full } \\
\text { participation }\end{array}$ & $\begin{array}{l}\text { the performance is evaluated by assigning } \\
\text { a score: } 0 \text { difficulty in all } 10 \text { no difficulty }\end{array}$ & $\begin{array}{l}\text { Is evaluated once used to stack coins } \\
\text { of different sizes }\end{array}$ \\
\hline
\end{tabular}




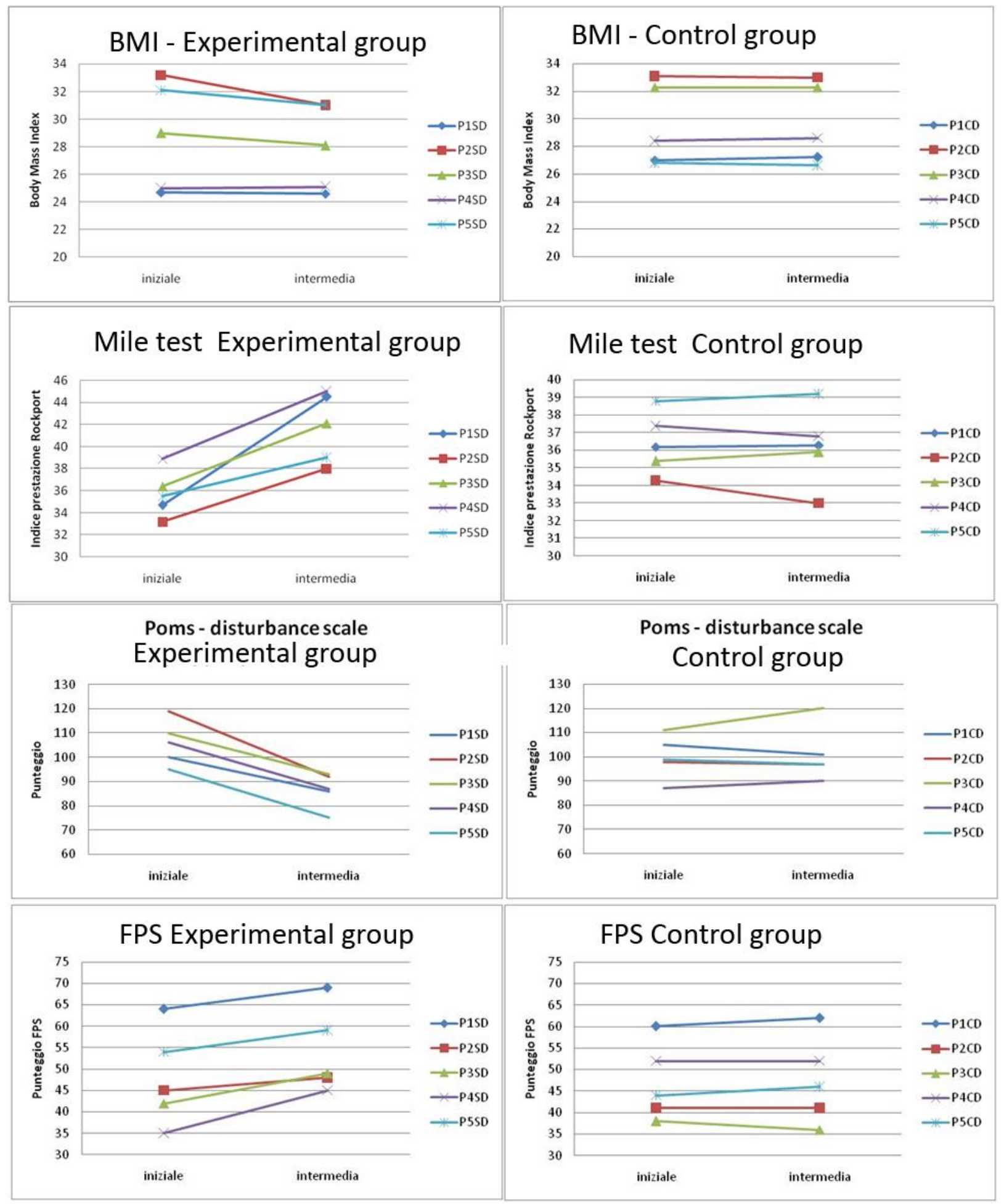

Figure 1. BMI, Mile test, poms and FPS in experimental and control group 


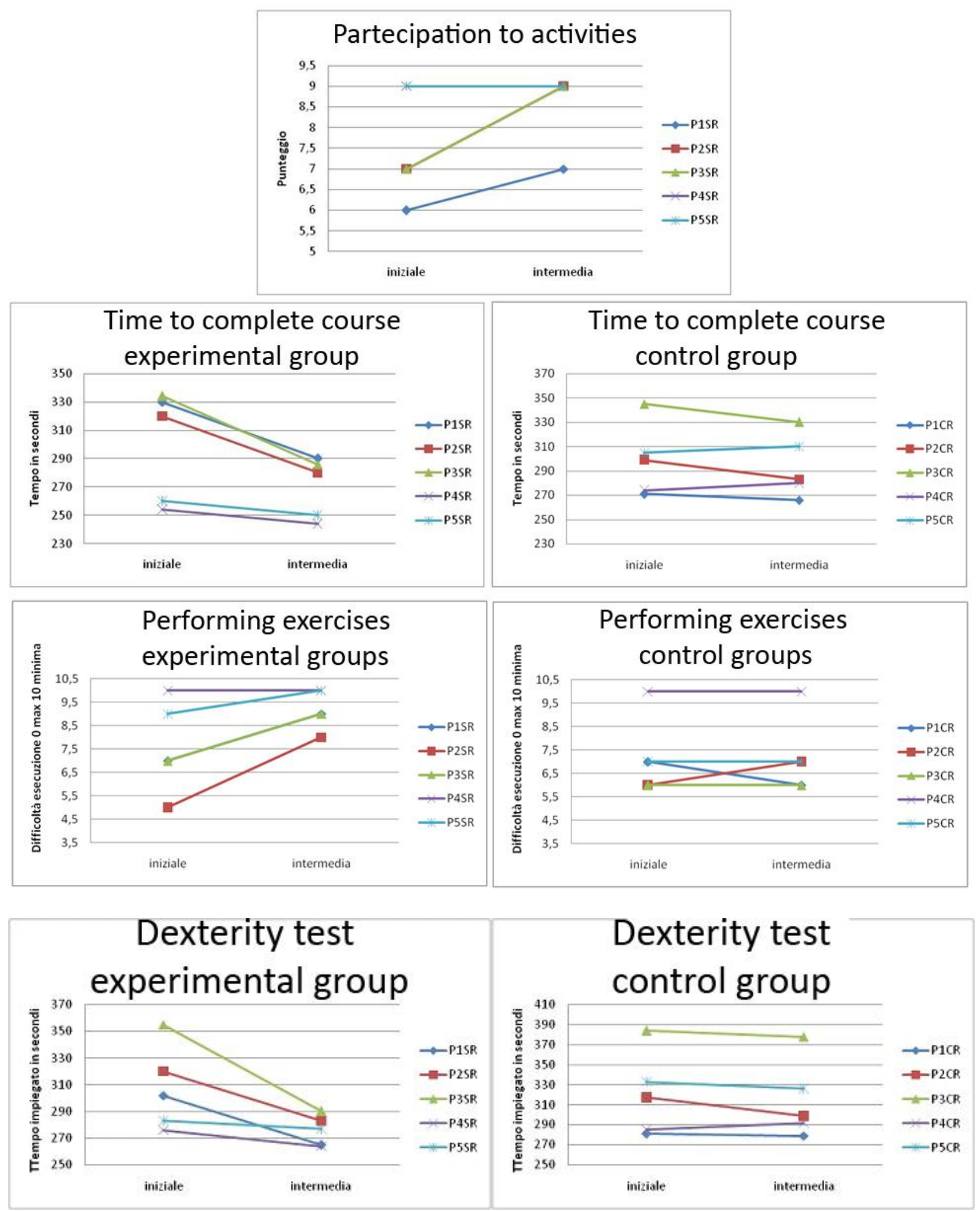

Figure 2. Participation, time to complete course, performing exercises and dexterity test in experimental and control group 


\section{DISCUSSION}

Analysis of the data are deduced the following reflections:

- The BMI of the experimental group tend to be most stable and downhill while in the control group did not appear to have significant variations.

- The mile test show that patients in the experimental group improved their performance index compared to the control group.

- The POMS test that indicates the state of mind of the patient with respect to the external stress show a marked decrease in the "distrurbance scale" in the experimental group. This implies an improvement in mood not found in the control group.

- Scores FPS show that the experimental patients have had appreciable improvements compared to the control group.

- The time to complete the course and the test of manual dexterity were positively affected by the activities carried out in the experimental group.

- Patients in the experimental group demonstrated better to be able to perform the exercises and then be the subject of preventive activity.

- Patients resident in facility prove to be able to adapt to the administration of these new activities.

\section{CONCLUSIONS}

The data collected if confirmed by the end of the pilot project to encourage the creation of an experimental project in which they are involved more patients and more facilities in order to evaluate the results.

\section{REFERENCES}

1. Altavilla, G., Tafuri, D., \& Raiola, G. (2014). Some aspects on teaching and learning by physical activity. Sport Science, 7(1), pp.7-9.

2. Alberti, M. (2009) Terapia Psicomotoria e Disturbo Psicotico. XIII Conferenza Nazionale della rete $\mathrm{HPH}$. Reggio Emilia: Centro Internazionale Loris Malaguzzi.

3. Biddle, S.J., Fox, K.R., \& Boutcher, S.H. (2000). Physical Activity and Psychological Well-Being. London: Routledge

4. Carozza, P. (2003). La riabilitazione psichiatrica nei Centri Diurni. Aspetti clinici e organizzativi. Milano: Franco Angeli.

5. Craft, L.L., \& Landers, D. (1998). The effect of exercise on clinical depression and depression resulting from mental illnes. Journal of Sport and Exercise Psycology, 20, pp.339-357.

6. Gaetano, R., Domenico, T., \& Gaetano A. (2015a). Physical activity and its relation to body and ludic expression in childhood. Mediterranean Journal of Social Sciences, 6(3).

7. Gaetano, R., Gomez, F.P., \& Gaetano, A. (2015b). Anxiety In The Youth Physical And Sport Activity. Mediterranean Journal of Social Sciences, 6(3).

8. Gaetano, R. (2012a). Didactics of volleyball into the educate program for coaches/trainers/technicians of Italian Federation of Volleyball (FIPAV). Journal of Physical Education and Sport, 12(2), pp.25-29.

9. Gaetano, R. (2012b). Motor learning and didactics into physical education and sport documents in middle school-first cycle of education in Italy. Journal of Physical Education and Sport, 12(2), pp.157-163.

10. Giuliani, A., Micacchi, G., \& Valenti, M. (2005). L'Attività Motoria nei servizi di salute mentale. Italian Journal Sport Sci, 12, pp.116-124. 
11. Gomez Paloma, F., Rio, L., \& D'Anna, C. (2014). Physical self-efficacy in women's artistic gymnastic between recreational and competitive level. Journal of Human Sport and Exercise, 9(1), pp.341-347.

12. Kurzthaler, I., Fleischhacker, W.W. (2001). The clinical implication of weight gain in schizophrenia. Journal of Clinical Psychiatry, 62(7), pp.32-37.

13. Raiola, G. (2015). Inclusion in sport dance and self perception. Sport Science, 8(1).

14. Raiola, G., \& Tafuri., D. (2015). Assestment and periodization in amateur soccer team. Sport science, 8(2).

15. Raiola, G., Tafuri, D., \& Paloma, G. (2014). Physical activity and sport skills and its relation to mind theory on motor control. Sport Science, 7(1), pp.52-56.

16. Raiola, G. (2014). Motor control and learning skills according to cognitive and ecological dynamic approach in a vision on behaviorism, cognitive, Gestalt and phenomenology heories. Mediterranean Journal of Social Sciences, 5(15), pp.504-506. 